\title{
Optimization of in vitro asymbiotic seed germination protocol for Serapias vomeracea
}

\author{
Arda Acemi* and Fazıl Özen
}

\begin{abstract}
Serapias vomeracea is an economically important orchid species which is over-collected from nature, because of its glucomannan-rich tubers. Thus, optimization of in vitro culture methodology in this species is required to meet industrial needs and to secure its populations in nature. This study aimed to optimize the surface sterilization protocol for $S$. vomeracea seeds and to select the optimal seed germination medium by comparing the commonly used media in in vitro orchid culture. During seed surface sterilization, ethyl alcohol $(\mathrm{EtOH})$ pre-treatment prior to sodium hypochlorite $(\mathrm{NaOCl})$ treatment increased the disinfection success and viable seed yield when examined using the triphenyl tetrazolium chloride (TTC) seed viability test. Also, low-g force centrifugation as an additional step in the surface sterilization method separated the seeds without embryo from the viable seeds and thereby decreased potential counting errors after incubation. Comparison of media showed that solid Knudson C (KN) medium induced the highest number of germinated seeds. However, seed germination success of Lindemann (LN) and Vacin \& Went (VW) media was found to be higher when the media was used in liquid form. Half-strength liquid VW was the only medium that induced higher germination success than the other full-strength media. The highest number of ungerminated seeds was found when using KN medium whereas liquid VW medium gave the lowest number. In general, protocorm formation was triggered when the media were used in liquid form. However, rhizoid elongation was suppressed in liquid media. These findings suggest that this optimized seed surface sterilization method offers a simple and effective alternative to classical methods. Additionally, solid KN medium may be considered as a cost-effective and reliable alternative to other commonly-used complex media in S. vomeracea cultures.
\end{abstract}

Keywords: Medium selection, method optimization, orchid seed germination, seed viability, surface sterilization

Department of Biology, Faculty of Arts and Sciences, Kocaeli University, İzmit, Kocaeli, Turkey

*Corresponding author: A. Acemi E-mail: arda.acemi@kocaeli.edu.tr

DOI: 10.2478/ebtj-2019-0017
(C) 2019 Authors. This work was licensed under the Creative Commons AttributionNonCommercial-NoDerivs 4.0 License.

\section{Introduction}

Serapias vomeracea is a wide-spread, perennial orchid species that can be found in arid meadows, on abandoned agricultural land and heathlands up to a height of $1000 \mathrm{~m}$. The plant's distribution extends over Mediterranean-Atlantic countries (Portugal, Spain, France, Italy, the Balkans, Greece, and Turkey). However, it is also found in North Africa (Morocco and Tunisia) where it is under high pressure of inbreeding depression (1). This species is one of the most widespread tuberous orchids in Turkey. Thus it is easily accessible in many cities and regions. Ease of accessibility in the environment and the economic value of its tubers make S. vomeracea one of the most collected orchid species from its native habitats (2). The component that makes the tubers of orchids so valuable is the polysaccharide glucomannan. Glucomannan is obtained from the tubers of orchids and the Konjac plant (Amorphophallus konjac). Glucomannan is currently used as a raw material for Salep production which is a traditional hot beverage in Turkey and is also used in food supplements, especially in weight loss capsules and other nutritional supplements, due to its hydrophilic properties (2). Also, the polysaccharide glucomannan is used as a thickener in the food industry and has been used to 


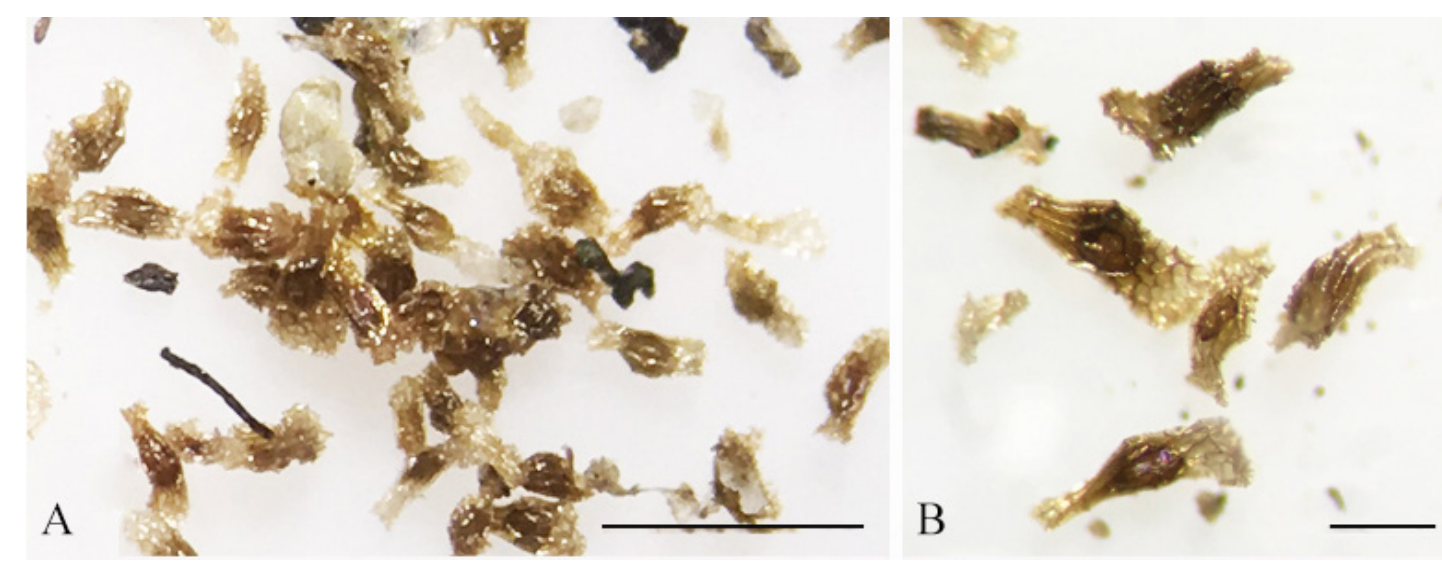

Figure 1. Stereomicroscope view of Serapias vomeracea seeds. A: $16 x$ magnification, the scale bar represents $0.5 \mathrm{~mm}$, B: $80 \mathrm{x}$ magnification, the scale bar represents $0.1 \mathrm{~mm}$.

treat high cholesterol $(3,4)$. Even though tuberous orchids are not yet extinct, there is evidence of population decline due to over-collection because of increasing commercial value and rising demand from industry. Therefore, an effective strategy should be designed, not only to conserve them in nature but also to take advantage of their economic potential through scientific investigation and development of commercially viable farming. One element of this strategy would be to develop and standardize both the optimum seed surface sterilization method and an efficient in vitro seed germination protocol that can be applied to economically valuable orchids including exotic hybrid ones, on a commercial scale.

As orchids can produce countless, dust-like seeds in their ovaries, the seeds have been mostly preferred as starting materials in tissue culture studies on terrestrial orchids (5). However, orchids are slow-growing plants in nature, and their seeds require a mycorrhizal relationship to germinate (6). Thus their seed germination rates are very low in nature. In contrast, in vitro cultures can offer an alternative for faster and more efficient production of orchids, and similar plants, that are difficult to germinate and develop in nature (7). Examination of various culture media, especially those developed mainly for orchids, can offer a detailed understanding of their nutritional requirements for in vitro germination.

In surface sterilization experiments of many in vitro germination studies, disinfectants such as ethyl alcohol (EtOH), sodium hypochlorite $(\mathrm{NaOCl})$, calcium hypochlorite $(\mathrm{CaOCl})$, hydrogen peroxide $\left(\mathrm{H}_{2} \mathrm{O}_{2}\right)$, silver nitrate $\left(\mathrm{AgNO}_{3}\right)$ and mercuric chloride $\left(\mathrm{HgCl}_{2}\right)$ have been commonly used (8). However, less toxic chemical compounds should be used in the surface sterilization treatment of orchid seeds since they have thin seed coats which make the embryo particularly vulnerable to toxic chemicals such as disinfectants (9). In this context, in addition to disinfectant selection, treatment duration is also important.

Another major factor is the method of surface sterilization used for orchid seeds. Orchid seeds are generally weighed and put into a pouch made from filter paper before they are dipped into disinfectants for surface sterilization following which they are sown using a scalpel or inoculation loop (10, 11). However, because the seeds are so small and difficult to handle a large number of seeds remain in the paper pouches.

As can be seen, there is scope for a range of improvements in the successful culturing of orchids including a selection of the optimal sterilizing agent, improved seed recovery following sterilization and selection of the optimal culture medium. Also, by investigating the optimal in vitro seed germination medium for Serapias vomeracea a better understanding of the plant's developmental physiology would be forthcoming, which would be of benefit in the development of controlled farming of this glucomannan-rich species for industrial purposes. Therefore, this study aimed to optimize the surface sterilization protocol for $S$. vomeracea seeds and to select the optimal seed germination medium by comparing the commonly used media in in vitro orchid culture.

\section{Materials and Methods}

\section{Seed source, and storage}

Seeds of Serapias vomeracea (Burm.f.) Briq. were used as starting material for in vitro cultures (Fig. 1). These seeds were obtained from the Directorate of Aegean Agricultural Research Institute (Menemen, İzmir, Turkey). The orchid seeds were kept dry and in the dark at $4{ }^{\circ} \mathrm{C}$ until they were used.

\section{Development of an efficient surface sterilization protocol}

The seeds were weighed to $1 \mathrm{mg}$ and then placed in roundbottom centrifuge tubes. In order to understand whether a pretreatment procedure was necessary for surface sterilization and to develop a more effective disinfection protocol, the seeds were divided into four groups and subjected to different sterilization treatments as shown in Table 1. During surface sterilization treatment, centrifuge tubes were stirred on a vortex shaker (Biosan Multi-Vortex V-32, Riga, Latvia). To reduce surface tension, $0.5 \mathrm{ml}$ of Tween-20 was added to the sterilization stock solutions. After surface sterilization procedures, the viable embryos were separated from empty seed coats by low $\mathrm{g}$ 
Table 1. Seed surface sterilization treatments tested on Serapias vomeracea seeds

\begin{tabular}{|c|c|c|}
\hline Treatment & Concentration (\%) & Time $(\mathbf{m i n})$ \\
\hline $\mathrm{NaOCl}$ & 0.5 & 8 \\
\hline $\mathrm{NaOCl}$ & 1.0 & 8 \\
\hline $\mathrm{EtOH}+\mathrm{NaOCl}$ & $70+0.5$ & $0.5+8$ \\
\hline $\mathrm{EtOH}+\mathrm{NaOCl}$ & $70+1.0$ & $0.5+8$ \\
\hline
\end{tabular}

centrifugation using the weight difference between viable seeds and non-viable seeds. The seed/sterilization mixtures were centrifuged at $2000 \mathrm{~g}$ for $1 \mathrm{~min}$ (CAPP CappRondo Microcentrifuge, Nordhausen, Germany). The non-viable seed coats were then removed with the supernatant using a micropipette whereas the seeds with embryo formed a loose pellet at the bottom of the tube. Finally, viable seeds were rinsed with sterile $\mathrm{H}_{2} \mathrm{O}$ to remove all traces of remaining $\mathrm{NaOCl}$. The used $\mathrm{H}_{2} \mathrm{O}$ was finally pipetted out from the tubes. To assess the success of the various surface sterilization treatments, the remaining seeds were sown onto Knudson C (KN) medium (12) and the cultures were observed for 30 days.

\section{Determination of seed viability}

The tetrazolium (2,3,5-Triphenyltetrazolium chloride; TTC) test, which is a reliable and validated method for various plant seeds, was used for determination of seed viability (5). TTC solution $1 \%(m: v)$ was freshly prepared before the test. TTC $(0.2 \mathrm{~g})$ was dissolved in $20 \mathrm{ml}$ of distilled water, $\mathrm{pH}$ was adjusted to 6.95 , the solution was sterilized through a syringe filter, and then it was stored in an amber bottle at $4{ }^{\circ} \mathrm{C}$ until use. The seeds were treated with $70 \% \mathrm{EtOH}$ for $2 \mathrm{~min}$ followed by $1 \%(m: v) \mathrm{NaOCl}$ for $10 \mathrm{~min}$. The seeds were divided into three groups prior to conducting the TTC test of seed viability after exposure to surface sterilization and $\mathrm{H}_{2} \mathrm{O}$ treatments. The first group of seeds was subjected to the TTC test without any prior treatment. The second group was left in the dark at $30{ }^{\circ} \mathrm{C}$ for $24 \mathrm{~h}$ in distilled water $\left(\mathrm{dH}_{2} \mathrm{O}\right)$, and then the TTC test was performed. The last group was subjected directly to the above-mentioned disinfection processes before the TTC test was applied. Each group of seeds was examined under a stereomicroscope (Olympus SZ61, Tokyo, Japan) following the TTC test and the stained seeds were counted.

\section{Preparation of seed germination media, and seed sowing}

In the experiments, $\mathrm{KN}$, Vacin and Went (VW), and Lindemann (LN) media $(13,14)$ were used in full and half strength $(1 / 2)$, both in solid (S) and liquid (L) forms. Thse formulations of the commercially available media are given in Table 2 . All media were supplemented with $20 \mathrm{~g} \mathrm{~L}^{-1}$ sucrose and, if solidified, with $3.5 \mathrm{~g} \mathrm{~L}^{-1}$ phytagel (Duchefa, Haarlem, The Netherlands). The $\mathrm{pH}$ of the media was set to 5.6 using $1 \mathrm{~N} \mathrm{NaOH}$ or $1 \mathrm{~N} \mathrm{HCl}$ before autoclaving at $121^{\circ} \mathrm{C}$ under pressure of $118 \mathrm{kPa}$ for 20 min (Nüve NC-40M, Ankara, Turkey). To transfer all the sur-
Table 2. Media compositions tested in in vitro germination of Serapias vomeracea seeds

\begin{tabular}{|c|c|c|c|}
\hline Content & \multicolumn{3}{|c|}{ Quantity (mg L-1) } \\
\hline Macroelements & $\mathrm{KN}$ & $\mathrm{VW}$ & $\mathrm{LN}$ \\
\hline $\mathrm{KNO}_{3}$ & & 525.000 & \\
\hline $\mathrm{NH}_{4} \mathrm{NO}_{3}$ & 500.000 & & \\
\hline $\mathrm{NH}_{4} \mathrm{H}_{2} \mathrm{PO}_{4}$ & 500.000 & & \\
\hline$\left(\mathrm{NH}_{4}\right)_{2} \mathrm{SO}_{4}$ & & 500.000 & 1000.000 \\
\hline $\mathrm{Ca}_{3}\left(\mathrm{PO}_{4}\right)_{2}$ & & 200.000 & \\
\hline $\mathrm{Ca}\left(\mathrm{NO}_{3}\right)_{2}$ & 347.200 & & 347.200 \\
\hline $\mathrm{MgSO}_{4}$ & 122.125 & 122.100 & 58.620 \\
\hline $\mathrm{KH}_{2} \mathrm{PO}_{4}$ & 250.000 & 250.000 & 135.000 \\
\hline $\mathrm{KCl}$ & 250.000 & & 1050.000 \\
\hline
\end{tabular}

Microelements

\begin{tabular}{|c|c|c|c|}
\hline $\mathrm{AlCl}_{3} \cdot 6 \mathrm{H}_{2} \mathrm{O}$ & & & 0.056 \\
\hline $\mathrm{NiCl}_{2} \cdot 6 \mathrm{H}_{2} \mathrm{O}$ & & & 0.031 \\
\hline $\mathrm{MnSO}_{4} \cdot \mathrm{H}_{2} \mathrm{O}$ & 5.682 & 5.600 & 0.052 \\
\hline KI & & & 0.099 \\
\hline $\mathrm{H}_{3} \mathrm{BO}_{3}$ & & & 1.014 \\
\hline $\mathrm{ZnSO}_{4} \cdot 7 \mathrm{H}_{2} \mathrm{O}$ & & & 0.565 \\
\hline $\mathrm{CuSO}_{4} \cdot 5 \mathrm{H}_{2} \mathrm{O}$ & & & 0.019 \\
\hline
\end{tabular}

Iron source

$\mathrm{C}_{6} \mathrm{H}_{5} \mathrm{FeO}_{7}$ 4.400

$\mathrm{FeSO}_{4} \cdot 7 \mathrm{H}_{2} \mathrm{O}$

25.000

27.800

\section{Complexing agent}

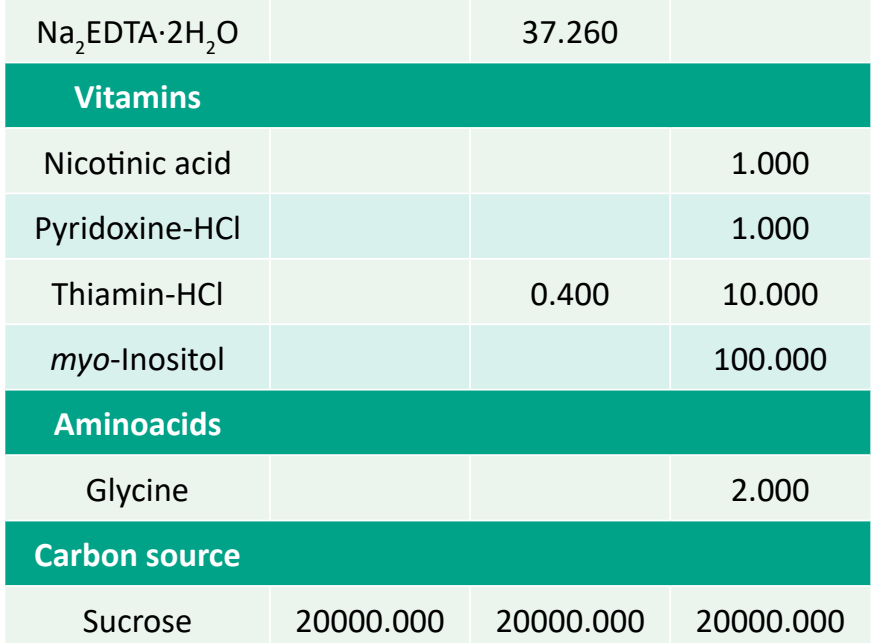


was added into the centrifuge tube after rinse water was carefully removed. The seeds were pipetted several times to ensure all the remaining seeds were dispersed in water. Finally, the seeds were 
Table 3. Stages of orchid seed germination according to Yamazaki and Miyoshi (2006)

\begin{tabular}{|c|c|} 
Germination stage & Indicators \\
Stage 0 & 'No germination' stage. No growth of embryo occurs. \\
Stage 1 & 'Pre-germination' stage. Embryo swells to fill the seed coat. \\
Stage 2 & 'Germination' stage. Embryo emerges from the seed coat. \\
Stage 3 & 'Protocorm' stage. Embryo is completely discharged from the seed coat. \\
Stage 4 & 'Rhizoid' stage. Rhizoids are formed on the protocorm surface. \\
Stage 5 & 'Shoot' stage. Shoot is differentiated from the protocorm.
\end{tabular}

transferred in sterile water and placed onto the desired medium using a micropipette. To disperse the seeds onto the medium, the Petri dishes were gently shaken after seed sowing.

\section{Culture conditions}

The solid cultures were incubated at $23 \pm 1^{\circ} \mathrm{C}$ in a plant growth chamber (Sanyo MLR-352H, Osaka, Japan) while a refrigerated and illuminated incubator shaker (New Brunswick Innova $42 \mathrm{R}, \mathrm{CT}$, USA) was used for the liquid cultures. The cultures were maintained under illumination of $60 \mu \mathrm{mol} \mathrm{m} \mathrm{m}^{-2} \mathrm{~s}^{-1}$ photosynthetic photon flux density with a 16 -h photoperiod. In order to reduce evaporation from the cultures, the relative humidity of the growth chamber was adjusted to $50 \%$ during the germination experiments.

\section{Seed count and statistical analysis}

The seeds were observed and counted by stereo microscope under 20-fold magnification at the end of a 45-day incubation period. The Petri dishes were divided into squares of $2 \times 2 \mathrm{~cm}$ in size for easier counting. Germination stages of the seeds were evaluated according to Yamazaki and Miyoshi (15). These stages are given in Table 3 . The germination percentages were calculated using the following formula for each medium (1).

(1) Germination percentage $(\%)=\Sigma$ Seed number (Stage $2-5) \times 100 / \Sigma$ Seed number (Stage $0-5)$

One milligram of seed $(\approx 180-200$ seeds $)$ per Petri dish was sown on each medium for seed surface sterilization and germination experiment. Each experiment was performed in triplicate. Surface sterilization success of the treatments was evaluated based on the observed bacterial and/or fungal contamination over 30 Petri dishes.

Seed germination and viability data were given as mean \pm standard deviation (SD). Means were compared using Duncan's Multiple Range Test (DMRT) at a significance level of $\mathrm{p}<0.05$. IBM SPSS Statistics software, version 22, was used for statistical analysis (IBM SPSS Statistics, Chicago, IL, USA).

\section{Results}

\section{Efficacy of surface sterilization method}

The combination of EtOH application for 30 seconds prior to $1.0 \% \mathrm{NaOCl}$ application for eight minutes fully inhibited contamination in the medium. Thus, this combination gave the most efficient surface sterilization result, and it was subsequently used in further experiments. However, a decrease in the concentration of $\mathrm{NaOCl}(0.5 \%)$ used in this combination resulted in the contamination of $23.33 \pm 5.77 \%$ of the cultures. When EtOH pretreatment was omitted, the contamination rate increased proportionally to the decrease in the concentration of $\mathrm{NaOCl}$. In the absence of $\mathrm{EtOH}$ pretreatment, treatment with $1.0 \% \mathrm{NaOCl}$ resulted in the contamination of $46.66 \pm 5.77 \%$ of the cultures while the highest contamination rate of $66.66 \pm 11.55 \%$ was observed in cultures exposed to $0.5 \% \mathrm{NaOCl}$.

\section{Seed viability}

The seeds which were kept in distilled water for one day showed a higher rate of viability on TTC test than those which

Table 4. Effects of different solid media on in vitro germination of Serapias vomeracea seeds

\begin{tabular}{|c|c|c|c|c|c|}
\hline \multirow{2}{*}{ Medium } & \multicolumn{5}{|c|}{ Seed germination stages (\%) } \\
\hline & Stage 0 & Stage 1 & Stage 2 & Stage 3 & Stage 4 \\
\hline KN & $15.04 \pm 2.68^{\mathrm{a}}$ & $26.19 \pm 5.32^{d}$ & $58.77 \pm 5.51^{a}$ & $0.00 \pm 0.00^{d}$ & $0.00 \pm 0.00^{b}$ \\
\hline $1 / 2 \mathrm{KN}$ & $13.04 \pm 2.16^{\mathrm{ab}}$ & $35.46 \pm 4.40^{c}$ & $51.51 \pm 3.13^{\mathrm{a}}$ & $0.00 \pm 0.00^{d}$ & $0.00 \pm 0.00^{b}$ \\
\hline VW & $9.75 \pm 0.98^{b c}$ & $46.00 \pm 5.16^{b}$ & $40.82 \pm 1.92^{b}$ & $2.83 \pm 0.30^{\mathrm{a}}$ & $0.79 \pm 0.10^{a}$ \\
\hline $1 / 2 V W$ & $7.45 \pm 0.47^{c}$ & $58.71 \pm 7.69^{a}$ & $33.71 \pm 7.11^{b c}$ & $0.13 \pm 0.05^{d}$ & $0.00 \pm 0.00^{b}$ \\
\hline LN & $13.86 \pm 3.25^{\mathrm{a}}$ & $57.64 \pm 2.16^{a}$ & $27.47 \pm 4.28^{c d}$ & $1.03 \pm 0.16^{c}$ & $0.00 \pm 0.00^{b}$ \\
\hline $1 / 2 \mathrm{LN}$ & $13.01 \pm 1.59^{\mathrm{ab}}$ & $61.22 \pm 4.95^{\mathrm{a}}$ & $23.55 \pm 5.23^{d}$ & $2.21 \pm 0.30^{b}$ & $0.00 \pm 0.00^{b}$ \\
\hline
\end{tabular}

Data represent mean \pm SD. Means having the same superscript letters in a column were not significantly different by Duncan's multiple range test $(p<0.05)$ 
Table 5. Effects of different liquid media on in vitro germination of Serapias vomeracea seeds

\begin{tabular}{|c|c|c|c|c|c|}
\hline \multirow{2}{*}{ Medium } & \multicolumn{5}{|c|}{ Seed germination stages (\%) } \\
\hline & Stage 0 & Stage 1 & Stage 2 & Stage 3 & Stage 4 \\
\hline KN & $11.85 \pm 1.36^{\mathrm{a}}$ & $34.35 \pm 3.55^{c}$ & $44.61 \pm 1.50^{b}$ & $8.46 \pm 0.88^{a}$ & $0.72 \pm 0.14^{\mathrm{a}}$ \\
\hline $1 / 2 K N$ & $9.43 \pm 1.80^{\mathrm{abc}}$ & $41.38 \pm 3.14^{b}$ & $46.75 \pm 1.31^{b}$ & $2.44 \pm 0.92^{b}$ & $0.00 \pm 0.00^{b}$ \\
\hline vW & $6.29 \pm 1.37^{c}$ & $41.91 \pm 0.10^{b}$ & $51.62 \pm 1.12^{\mathrm{a}}$ & $0.17 \pm 0.03^{c}$ & $0.00 \pm 0.00^{b}$ \\
\hline $1 / 2 \mathbf{V W}$ & $7.94 \pm 1.52^{\mathrm{bc}}$ & $36.91 \pm 3.42^{\mathrm{bc}}$ & $52.41 \pm 2.34^{\mathrm{a}}$ & $2.74 \pm 0.25^{b}$ & $0.00 \pm 0.00^{b}$ \\
\hline LN & $10.98 \pm 2.07^{\mathrm{ab}}$ & $48.19 \pm 1.91^{\mathrm{a}}$ & $40.24 \pm 1.88^{c}$ & $0.60 \pm 0.06^{c}$ & $0.00 \pm 0.00^{b}$ \\
\hline $1 / 2 \mathrm{LN}$ & $10.55 \pm 2.26^{\mathrm{ab}}$ & $50.60 \pm 2.57^{\mathrm{a}}$ & $38.66 \pm 2.77^{c}$ & $0.19 \pm 0.00^{c}$ & $0.00 \pm 0.00^{b}$ \\
\hline
\end{tabular}

Data represent mean \pm SD. Means having the same superscript letters in a column were not significantly different by Duncan's multiple range test $(p<0.05)$

were not, after surface sterilization. The viability percentage of the seeds kept in $\mathrm{dH}_{2} \mathrm{O}$ before surface sterilization was found to be $54.67 \pm 4.16$ while viability percentage was found to be $43.67 \pm 3.06$ in response to direct surface sterilization without prior $\mathrm{dH}_{2} \mathrm{O}$ treatment. Direct application of TTC test without any surface sterilization treatment on the seeds resulted in $41.66 \pm 2.89 \%$ viability. Consequently, sterilization treatment slightly increased seed viability when calculated by the TTC test, but $\mathrm{dH}_{2} \mathrm{O}$ pretreatment made the most significant contribution to seed viability.

Effect of type and physical state of media on germination of the seeds

The detailed germination data are given in Table 4 and 5 for solid and liquid media, respectively. The highest number of stage 0 seeds was found from KN medium both in solid and liquid phases. In general, liquid media resulted in fewer stage 0 seeds than solid media. The lowest number of stage 0 seeds was found when liquid VW medium was used. All half-strength solid media resulted in fewer stage 0 seeds than full-strength solid media. Only half-strength VW medium gave a slightly higher number of stage 0 seeds than its full-strength variant. Solid LN and KN media gave statistically the same stage 0 seed percentages. Stage 1 seeds were observed in higher numbers from both solid and liquid LN medium while KN medium induced the lowest number of stage 1 seeds (Fig. 2A). Among the tested liquid media, full- and half-strength LN media gave statistically the same result for stage 1 seed percentages while a similar statistical result was obtained using half-strength VW, full strength LN and half-strength LN. All half-strength solid media induced a higher percentage of stage 1 seeds than fullstrength solid media. Solid KN medium gave the highest proportion of stage 2 seeds than other media (Fig. 2B). However, the results from full- and half-strength $\mathrm{KN}$ medium both in solid and liquid phases were statistically the same. Using liquid media, more stage 2 seeds were counted when cultured in full- and half-strength VW medium. The results obtained from these media were statistically the same. The lowest number of stage 2 seeds was counted when cultured in half-strength LN medium both in liquid and solid phases. For stage 3 seed induction the most successful medium was solid VW whereas no

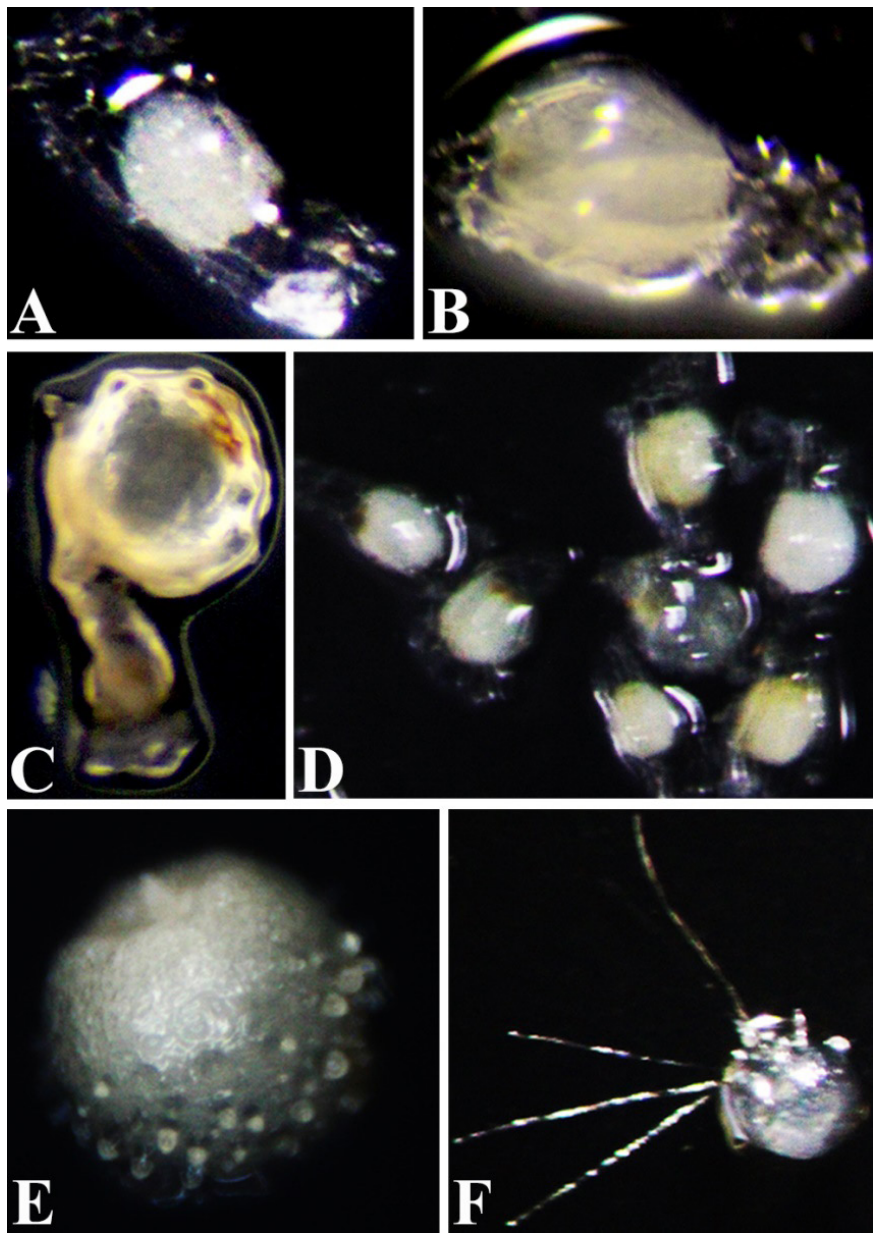

Figure 2. Germination stages of Serapias vomeracea seeds. A: Stage 1 seed in solid KN medium, B: Stage 2 seed at the beginning of germination in solid KN medium, C: Stage 3 seed from solid VW medium, D: General view of stage 3 seeds in liquid KN medium, E: Stunted rhizoids of the seed in liquid medium, F: Elongated rhizoids on solid VW medium.

stage 3 seeds were observed from solid $\mathrm{KN}$, regardless of the medium strength. All other solid media induced stage 3 seed development (Fig. 2C). However, liquid KN medium gave the highest percentage of stage 3 seeds while the lowest percentage was found when using liquid VW medium. It was observed that liquid media triggered the formation of the protocorm 


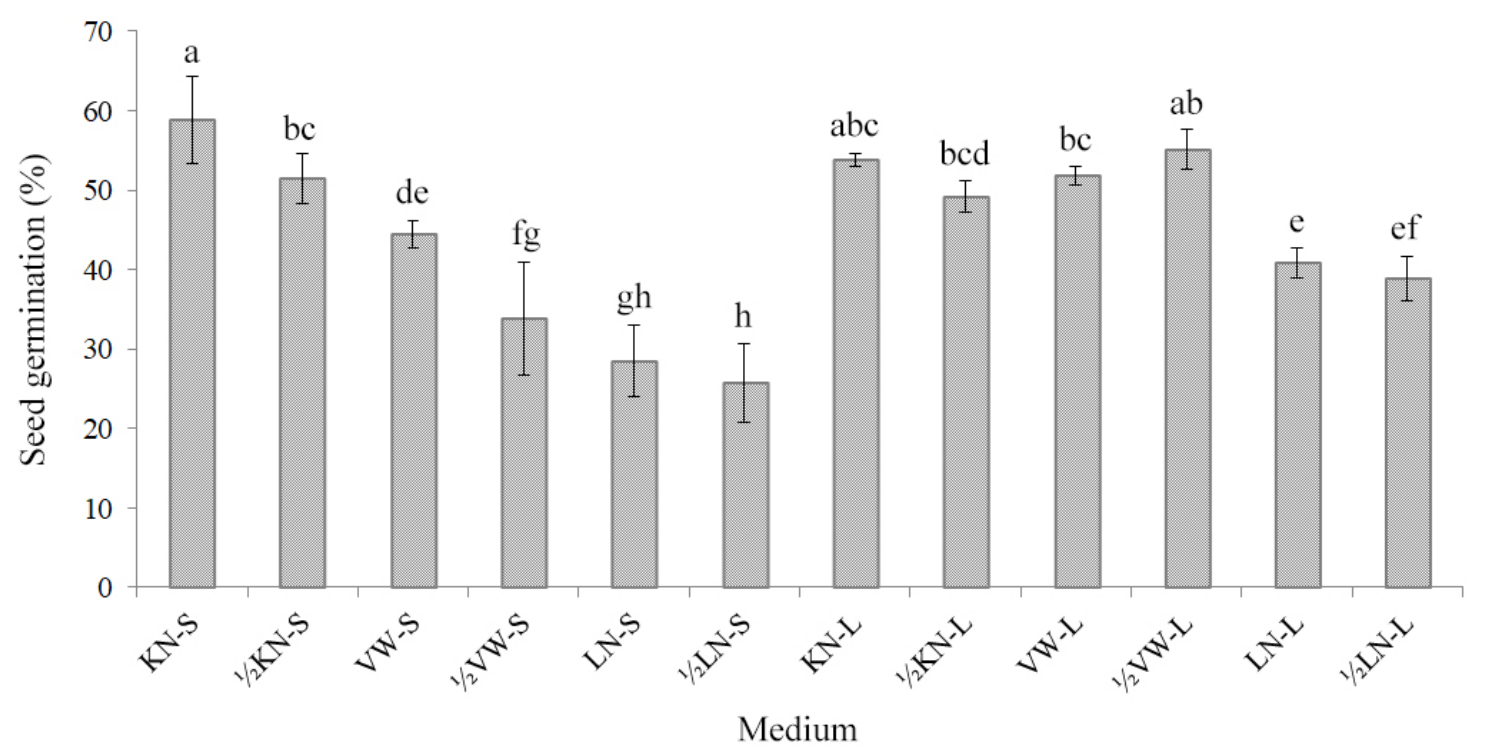

Figure 3. Comparison of in vitro germination rates of Serapias vomeracea seeds on solid and liquid media. Data represent mean \pm SD. Means having the same superscript letters in a column were not significantly different by Duncan's multiple range test ( $p<$ 0.05).

(stage 3 germination) more successfully than solid media (Fig. 2D). Only culturing with solid VW and liquid KN medium resulted in stage 4 seed germination. The solid VW medium gave slightly better results than liquid KN medium with the rhizoids of stage 4 seeds on the solid medium being longer than that of liquid media-germinated seeds (Figs. $2 \mathrm{E}$ and $2 \mathrm{~F}$ ). No stage 5 seeds were observed in any of the media tested regardless of strength or form. Considering the germination parameters for orchid seeds, all seeds found at stage 2 or later were considered to have germinated. When the data were analyzed in this way, solid KN medium was found to be the best germination medium for $S$. vomeracea seeds $(58.77 \pm 5.51 \%)$, whereas semistrength solid LN medium gave the lowest seed germination percentage (25.76 $\pm 4.93 \%$ ) (Fig. 3). In addition, germinated seeds on KN medium successfully progressed towards subsequent developmental stages with prolonged incubation.

\section{Discussions}

When using seeds as starting materials in tissue culture studies the most important measure of success is the percentage of the seeds which germinate. Successful germination will be due to the fact that the seeds cultured on the medium receive water and swell and take macro- and microelements from the medium (16). Therefore, it is necessary to eliminate the waxy compounds that may prevent the water from entering through the seed coat and thus to convey a hydrophilic nature to the seeds (17). It has been shown that ethyl alcohol provides a hydrophilic structure to the coats of orchid seeds by eliminating pectin, suberin and other waxy compounds present on the coat, thereby ensuring effective contact with $\mathrm{NaOCl}$ during surface sterilization (18). In addition, the same researchers reported that pretreatment with EtOH significantly increases germination percentages. Although the composition of hydrophobic compounds on the seed coat varies from species to species, the improved results with EtOH showed that the hydrophobic compounds on the seed coat of $S$. vomeracea might be too dense to be eliminated by $\mathrm{NaOCl}$ sterilization alone. Ponert et al. (18) also recommended placing the seeds in a syringe during surface sterilization treatment in order to prevent seed loss during sowing. In addition, it should be noted that since the microbial load of orchid seeds may differ, the durations of the surface sterilization applications may vary for each study. The seed quantity is also another important factor affecting the success and the length of the surface sterilization process. For example, Ercole et al. (19) used $25 \mathrm{mg}$ of S. vomeracea seeds per centrifuge tube but subjected them to $1 \mathrm{ml}$ of $1 \% \mathrm{NaO}$ $\mathrm{Cl}$ solution for $20 \mathrm{~min}$. In that study, no seed viability test was employed, but the authors reported higher germination rates of up to $95 \%$ in symbiotic cultures on solid oat medium. However, the authors did not assess the developmental stages of the seeds. Furthermore, considering that $1 \mathrm{mg}$ of $S$. vomeracea seeds would be between 180-200 individual seeds, counting $25 \mathrm{mg}$ of seeds under the microscope at the beginning, middle and the end of the incubation period would be much more time-consuming than our method, and may result in counting inaccuracy due to human error.

In this study, the effectiveness of the TTC test was increased by keeping the seeds in $\mathrm{dH}_{2} \mathrm{O}$ for 24 hours. The reason for this is likely to be due to the onset and/or acceleration of metabolic activities in the seeds receiving water. An additional effect may be because of the increased permeability of the seed coat due to the oxidation of lignin (20). In a study on Orchis coriophora, Bektas et al. (21) incubated the seeds in 5\% sucrose with several drops of commercial bleach solution for 12 hours before the TTC test. Seed viability was found to be $54 \pm 2.1 \%$. However, in a similar study on $S$. vomeracea, the result of seed viability was not indicated (22). Plant seeds need a carbon and energy source until they germinate and become autotrophic when cultured in 
vitro (23). This is more evident in non-endosperm-containing orchid seeds. Therefore, sucrose application may increase seed viability results on the TTC test by also accelerating metabolic activities.

The seeds of epiphytic and terrestrial orchids have been reported to germinate faster and contain more water when they are grown symbiotically. This is because mycorrhizal fungi increase the seed germination rate by facilitating water, carbon and nutrients intake (24). Thus, the length of germination time in asymbiotic cultures may be related to the slower water, carbon and nutrients intake (25). In this study, although solid KN medium was found to be the best overall inducer of germination, higher germination rates were generally observed from liquid media. This finding suggests that liquid media facilitates easier intake of water and other required nutrients compared with solid media. In this context, epiphytic Doritaenopsis orchid cultures have been reported to germinate faster in liquid medium than solid medium, but the overall germination rate remained the same at the end of the incubation period (26). A general observation from our study was that at the end of extended incubation periods the rhizoids of the protocorms were much shorter in liquid media, but in the solid media, the rhizoids developed normally. This may be related to the pressure and/or surface tension of the liquid culture on the protocorms and/or to easier access of the protocorms to nutrients. Rhizoids are primitive root precursors and conduits for nutrients to the protocorms. Rhizoids also play a role as carbohydrate depositories for subsequent stages of growth (27). Since the seeds float in liquid media and are not present on a single solid surface as with solid media, there are disadvantageous in using liquid media during the seed counting step. Also, it is necessary to agitate the cultures during incubation to prevent elements and the seeds precipitating in liquid media. For all these reasons, it is recommended to use solid media for culturing $S$. vomeracea.

Compared to LN medium used in the experiments, $\mathrm{KN}$ and VW media are the simplest ones in terms of microelements, vitamins, and amino acids. However, both media gave the highest seed germination results among the liquid cultures. Macroelements cover the largest portion in culture medium composition. Therefore, this difference in germination success can be attributed to the differences between the macroelement compositions of the media. LN medium contains $46 \%$ less of $\mathrm{KH}_{2} \mathrm{PO}_{4}$ than $\mathrm{KN}$ and VW medium. VW medium contains $\mathrm{Ca}_{3}\left(\mathrm{PO}_{4}\right)_{2}$ while $\mathrm{KN}$ medium contains $\mathrm{NH}_{4} \mathrm{H}_{2} \mathrm{PO}_{4}$ which act as additional phosphate sources. Therefore, the success of germination of these liquid culture media may be due to increased availability of phosphate to the seeds. Rich phosphate content in Mishra medium was found to be responsible for increased seed germination rates in Cymbidium eburneum (28). In nature, enhanced plant development due to increased phosphate uptake as a result of mycorrhizal symbiosis was reported for Goodyera repens (29). Rodrigues et al. (30) stated that the initial phosphorus $(\mathrm{P})$ demand in young orchid plants may be greater than that of adult plants. Therefore, phosphate-rich media should be considered in asymbiotic germination of $S$. vomer- acea seeds. However, KN medium which had the highest seed germination rate, is also distinguished from the other media by the higher total nitrogen ratio, mainly coming from $\mathrm{NH}_{4} \mathrm{NO}_{3}$ and $\mathrm{Ca}\left(\mathrm{NO}_{3}\right)_{2}$. Thus, the success of germination in solid media may also be related to the presence of nitrate, which is present in much greater amounts than phosphate. Furthermore, in addition to organic carbon, nitrogen $(\mathrm{N})$ is probably a major nutrient transferred to the plant because orchid tissues are highly nitrogen-enriched (31). Similar to the findings obtained in this study, Gümüş and Ellialtıoğlu (11) reported that the highest germination rate of $S$. vomeracea seeds (76.85\%) was found when using $\mathrm{KN}$ medium, whereas seed germination decreased down to $47.51 \%$ after a reduction of inorganic nitrogen sources from the medium. They supplemented the KC medium with $20 \mathrm{~g} \mathrm{~L}^{-1}$ sucrose but collected the germination data after $90 \mathrm{~d}$ of incubation in the dark. Bektaş and Sökmen (22) stated that the germination rate of $S$. vomeracea seeds in $\mathrm{KN}$ medium without sucrose was only $27.95 \pm 2.4 \%$ after 60 days of incubation. Furthermore, at the same incubation period, the authors reached to $73.74 \pm 1.6 \%$ germination ratio after testing Orchimax medium which is enriched by trypton to provide an additional source of reduced organic nitrogen, vitamins and nutritional agents. The medium also includes activated charcoal and MES 2-(N-Morpholino)ethanesulfonic acid buffer. However, the authors showed that absence of activated charcoal in Orchimax medium reduced the germination ratio down to $43.11 \pm 1.5 \%$. Therefore, the main effective component is activated charcoal in this complex medium. In our study, we showed that there is no need to use such a complex medium, but simple Knudson $\mathrm{C}$ medium can offer an easy-to-prepare and cost-effective alternative to other complex media. In the present study, $58.77 \pm 5.51 \%$ of the seeds germinated on sucrose-enriched $\mathrm{KN}$ medium after 45 days of incubation. It is evident that the germination percentage of the seeds is closely related to the extent of the incubation period. If the incubation period is extended, more germinated seeds will be counted. $\mathrm{KN}$ medium showed high germination rates also for Calopogon tuberosus var. tuberosus (32), Dendrobium aphyllum, Rhyncostlis retusa, Cymbidium longifolium (33) and C. aloifolium cultures (34). Our results also showed that glycine amino acid and vitamins such as nicotinic acid, pyridoxine, thiamin, and myo-inositol which are completely absent from KN media and largely absent from VW media are not required for the germination of $S$. vomeracea seeds. However, at subsequent developmental stages, the nutritional needs of the plant would differ.

\section{Conclusion}

The additional low-g centrifugation treatment in our seed surface sterilization method successfully separated empty seed coats (with no embryo) from the seeds with embryos using their mass difference. This method is ideal for eliminate counting errors, especially for stage 0 and 1 seeds, since it removes the non-viable seed coats before sowing. Here, a rapid pre-treatment with $\mathrm{EtOH}$ is also advised to enhance the effectiveness of the TTC test to achieve more reliable results. Our study showed 
that the use of solid KN medium appears to be the optimum choice for $S$. vomeracea seed culture germination. The medium is known for its simplicity and ease of preparation while offering various modification possibilities that can enhance germination success. Based on the KN medium, the addition of several growth regulators such as auxin or cytokinin derivatives, or promoters such as oligomeric or polymeric chitosans, natural carbon sources such as banana homogenate or coconut water may enhance the effectiveness of $\mathrm{KN}$ medium in germinating $S$. vomeracea seeds, but further study would be required to confirm this. The outcome of this study suggests that our improved surface sterilization method and use of a solid KN medium may be a simple, cost-effective and reliable alternative to commonly used sterilization methods and use of other more complex media for S. vomeracea cultures.

\section{Acknowledgments}

The authors would like to thank Mr. Jeremy Jones, of the Kocaeli University Academic Writing Department, for his help with the English used in this paper.

\section{Conflict of Interest}

The authors declare that they have no conflicts of interest.

\section{Ethical Compliance}

This article does not contain any studies involving human participants or animals performed by any of the authors.

\section{References}

1. Bellusci F, Pellegrino G, Musacchio A. Different levels of inbreeding depression between outcrossing and selfing Serapias species (Orchidaceae). Biol Plant 2009; 53: 175-178.

2. Acemi A, Çobanoğlu Ö, Türker-Kaya S. FTIR-based comparative analysis of glucomannan contents in some tuberous orchids, and effects of pre-processing on glucomannan measurement. J Sci Food Agric 2019; 99: 3681-3686.

3. Arvill A, Bodin L. Effect of short-term ingestion of konjac glucomannan on serum cholesterol in healthy men. Am J Clin Nutr 1995; 61: 585-589.

4. Sood N, Baker LW, Coleman Cl. Effect of glucomannan on plasma lipid and glucose concentrations, body weight, and blood pressure: Systematic review and meta-analysis. Am J Clin Nutr 2008; 88: 1167-1175.

5. Arditti J. Micropropagation of orchids $2^{\text {nd }}$ ed., Blackwell Publishing, UK, 2008.

6. Rasmussen HN, Dixon KW, Jersáková J, Těšitelová T. Germination and seedling establishment in orchids: a complex of requirements. Ann Bot 2015; 116: 391-402.

7. Paul S, Kumaria S, Tandon P. An effective nutrient medium for asymbiotic seed germination and large-scale in vitro regeneration of Dendrobium hookerianum, a threatened orchid of northeast India, AoB Plants 2012; plr032.

8. Yeung EC, Park J, Harry IS. Orchid seed germination and micropropagation I: Background information and related protocols; pp. 101-125 in Lee Yl; Yeung ET (Eds) Orchid Propagation: From laboratories to greenhouses-Methods and protocols. New York, Springer Protocols Handbooks, Humana Press, 2018.

9. Katsalirou E, Gerakis A, Haldas X, Deconninck G. Optimal disinfection times for seeds of Mediterranean orchids propagated on nutrient media. Eur J Environ Sci 2017; 7: 119-124.
10. Özkoç I, Dalcı M. Germination of the seeds of Orchis laxiflora Lam. (Orchidaceae) through asymbiotic culture techniques. Turk J Bot 1994; 18: 461-464.

11. Gümüş C, Ellialtıoğlu Ş. Seed germination and development of Serapias vomeracea (Burm. fil.) Briq. ssp. orientalis Greuter in tissue culture. Res J Biotechnol 2012; 7: 4-8.

12. Knudson L. A new nutrient solution for germination of orchid seed. Amer Orchid Soc Bull 1946; 15: 214-217.

13. Vacin $\mathrm{E}$, Went FW. Some $\mathrm{pH}$ changes in nutrient solutions. Bot Gaz 1949; 110: 605-613.

14. Lindemann EG, Gunckel JE, Davidson OW. Meristem culture of Cattleya, Amer Orchid Soc Bull 1970; 39: 1002-1004.

15. Yamazaki J, Miyoshi K. In vitro asymbiotic germination of immature seed and formation of protocorm by Cephalanthera falcata (Orchidaceae), Ann Bot 2006; 98: 1197-1206.

16. Yeung EC. A perspective on orchid seed and protocorm development. Bot Stud 2017; 58: 33.

17. Kauth PJ, Dutra D, Johnson TR, Stewart SL, Kane ME, Vendrame W. Techniques and applications of in vitro orchid seed germination; pp. 375-391 in Teixeira da Silva, J.A. (Ed.) Floriculture, Ornamental and Plant Biotechnology: Advances and Topical Issues. Isleworth, UK, Global Science Book, 2008.

18. Ponert J, Vosolsobê S, Kmecová K, Lipavská H. European orchid cultivation - from seed to mature plant. Eur J Environ Sci 2011; 1: 95-107.

19. Ercole E, Rodda M, Girlanda M, Perotto S. Establishment of a symbiotic in vitro system between a green meadow orchid and a Rhizoctonia-like fungus. Bio-protocol 2015; 5(10): e1482.

20. Barsberg S, Rasmussen HN, Kodahl N. Composition of Cypripedium calceolus (Orchidaceae) seeds analyzed by attenuated total reflectance ir spectroscopy: In search of understanding longevity in the ground. Am J Bot 2013; 100(10): 2066-2073.

21. Bektaş $E$, Cüce $M$, Sökmen $A$. In vitro germination, protocorm formation and plantlet development of Orchis coriophora (Orchidaceae), a naturally growing orchid species in Turkey. Turk J Bot 2013; 37: 336-342.

22. Bektaş E, Sökmen A. In vitro seed germination, plantlet growth, tuberization, and synthetic seed production of Serapias vomeracea (Burm.f.) Briq. Turk J Bot 2016; 40: 584-594.

23. Zahara M, Datta A, Boonkorkaew P, Mishra A. The effects of Different media, sucrose concentrations and natural additives on plantlet growth of Phalaenopsis hybrid 'Pink'. Braz Arch Biol Technol 2017; 60: e17160149.

24. De Long JR, Swarts ND, Dixon KW, Egerton-Warburton LM. Mycorrhizal preference promotes habitat invasion by a native Australian orchid: Microtis media. Ann Bot 2012; 111: 409-18.

25. Yoder JA, Zettler LW, Stewart SL. Water requirements of terrestrial and epiphytic orchid seeds and seedlings, and evidence for water uptake by means of mycotrophy. Plant Sci 2000; 156: 145-150.

26. Tsai W-T, Chu C-Y. Static liquid culture of Doritaenopsis seedlings. Hortscience 2008; 43: 206-210.

27. Edwin FG. Plant propagation by tissue culture. Exegetics Ltd., Edington Wilts, UK, 1993.

28. Gogoi K, Kumaria S, Tandon P. Ex situ conservation of Cymbidium eburneum Lindl.: a threatened and vulnerable orchid, by asymbiotic seed germination. 3 Biotech 2012; 2: 337.

29. Alexander C, Alexander IJ, Hadley G. Phosphate uptake by Goodyera repens in relation to mycorrhizal infection. New Phytol 1984; 97: 401-411.

30. Rodrigues DT, Novais RF, Alvarez VH, Dias JMM, Villani EMA. Orchid growth and nutrition in response to mineral and organic fertilizers. Rev Bras Cienc Solo 2010; 34: 1609-1616.

31. Fochi V, Chitarra V, Kohler A, Voyron S, Singan VR, Lindquist EA, Barry KW, Girlanda M, Grigoriev IV, Martin F, Balestrini R, Perotto S. Fungal and plant gene expression in the Tulasnella calospora 
- Serapias vomeracea symbiosis provides clues about nitrogen pathways in orchid mycorrhizas. New Phytol 2017; 213: 365-379.

32. Kauth PJ, Vendrame W, Kane ME. In vitro seed culture and seedling development of Calopogon tuberosus. Plant Cell Tissue Organ Cult 2006; 85: 95-102.

33. Das AK, Das J, Gogoi HK, Srivastava RB. Mass propagation of orchids through in vitro seed culture technology. J Cell Tissue Cult Res 2008; 8: 1585-1588.

34. Philip RJ, Kakati JP, Sebestinraj J, Suriya K. In vitro seed germination of Cymbidium aloifolium (L.) Sw., a potential medicinal orchid from Eastern Ghats of Tamil Nadu, India. J Plant Biotechnol 2017; 44: 343-348. 